Editorial

\title{
Cement-Based Composites: Advancements in Development and Characterization
}

\author{
Pawel Sikora ${ }^{1,2, * \mathbb{D}}$ and Sang-Yeop Chung ${ }^{3, *}$ \\ 1 Building Materials and Construction Chemistry, Technische Universität Berlin, Gustav-Meyer-Allee 25, \\ 13355 Berlin, Germany \\ 2 Faculty of Civil and Environmental Engineering, West Pomeranian University of Technology, Al. Piastow 50, \\ 70-311 Szczecin, Poland \\ 3 Department of Civil and Environmental Engineering, Sejong University, 209 Neungdong-ro, Gwangjin-gu, \\ Seoul 05006, Korea \\ * Correspondence: pawel.sikora@zut.edu.pl (P.S.); sychung@sejong.ac.kr (S.-Y.C.)
}

Received: 16 September 2020; Accepted: 17 September 2020; Published: 17 September 2020

check for updates

\begin{abstract}
This Special Issue on "Cement-Based Composites: Advancements in Development and Characterization" presents the latest research and advances in the field of cement-based composites. This special issue covers a variety of experimental studies related to fibre-reinforced, photocatalytic, lightweight, and sustainable cement-based composites. Moreover, simulation studies are present in this special issue to provide the fundamental knowledge on designing and optimizing the properties of cementitious composites. The presented publications in this special issue show the most recent technology in the cement-based composite field.
\end{abstract}

Keywords: cement-based composite; experimental studies; numerical simulation; sustainability

\section{Introduction}

Concrete, a composite material composed of cement, water, aggregates, and often admixtures, is the most produced human-made material in the world. This material is an indispensable element of modern societies and is used in most of today's constructed engineering structures. Concrete structures need to satisfy specific characteristics in terms of mechanical performance and long-term durability so that they can be used without serious consideration of maintenance for many decades. Therefore, proper methods to produce advanced high-performance composites are actively required. Due to their composite nature, the choice of proper individual components and their interaction and compatibility plays a vital role in shaping the final properties of cement-based composites. In addition, there is a strong need to develop sustainable cementitious composites as well as their alternatives to tackle the challenge of increasing total anthropogenic carbon dioxide emissions. Therefore, numerical approaches to modeling and evaluating a material's characteristics and properties can also be used to accelerate the material's development.

This Special Issue on "Cement-Based Composites: Advancements in Development and Characterization" presents the latest research and advances in the field of cement-based composites.

\section{Contents of this Special Issue}

Marcalikova et al. [1] performed a study on the effects of two types of fibers (hooked and straight) on the quantitative and qualitative parameters of concrete. The fibers were hooked and straight. The influence of the fibers type and content on the mechanical properties in fiber-reinforced concrete was analyzed by functional dependence. Comprehensive evaluations of the mechanical properties of compressive strength, splitting tensile strength, bending tensile strength, and fracture energy 
were performed. Moreover, the resulting load-displacement diagrams and summary recommendations for the structural use and design of fiber-reinforced concrete structures were presented.

Smarzewski [2] conducted his research on local bond strength of short length specimens in high-performance concrete (HPC) and basalt fibre reinforced high-performance concrete (BFRHPC). As the main variables in this study, the basalt fibre volume content, concrete cover, bar diameter, and rib geometry were chosen. Moreover, additional factors were the directions of the casting and loading. For different ranges of BFRHPC strength, relationships for bond strength concerning the splitting tensile strength were obtained. The study showed that the bond strength increased with the splitting tensile strength and compressive strength of BFRHPC specimens with the $12 \mathrm{~mm}$ and $16 \mathrm{~mm}$ bar respectively. Moreover, the bond strength of BFRHPC was lower for the bar with the greater distances between the lugs on the bar.

In the study by Jiang et al. [3], a new mixture composition of steel fiber-reinforced $\mathrm{MgO}$ concrete (SFRMC) was proposed and evaluated to combine positive effects of both fiber-reinforced concrete and expansion concrete. The influence of steel fiber and $\mathrm{MgO}$ on the strength and chloride diffusion resistance of concrete was evaluated by splitting tensile test and chloride diffusion test. The results showed that the combined action of steel fiber and $\mathrm{MgO}$ reduced the porosity of concrete and the chloride diffusion coefficient, which could not be achieved by steel fiber and $\mathrm{MgO}$ separately. Moreover, mercury intrusion porosimeter (MIP) and scanning electron microscopy (SEM) confirmed that newly developed concretes exhibit lower porosities than reference concrete.

Cheng et al. [4] performed a study on the unconfined compression strength of polypropylene fiber-reinforced composite cemented clay. Three main factors, including polypropylene fiber content, composite cement content, and curing time on the unconfined compressive strength of fiber-reinforced cemented clay, were studied. The authors concluded that the incorporation of fibers can increase the compressive strength and residual strength of cement-reinforced clay as well as the corresponding axial strain when the stress peak is reached compared with cement-reinforced clay. The compressive strength of fiber-composite cement-reinforced marine clay increases with the increase of curing time and composite cement content. Moreover, differences in the failure mode in specimens were found: cement-reinforced clay is a brittle failure, while the failure mode of fiber-reinforced cemented clay is a plastic failure.

Lehner et al. [5] evaluated the chloride ion diffusion coefficient of self-compacting concrete with steel-fibre reinforcement. Data was compared with Ordinary Portland Cement (OPC). Three different procedures of diffusion coefficient calculation were presented namely: rapid chloride penetration test accelerated penetration tests with chloride, and surface measurement of electrical resistivity using Wenner probe. The resulting diffusion coefficients obtained by all methods are compared and evaluated regarding the basic mechanical properties of concrete mixtures. Meaningful relations between the testing methods and steel fibers content were established.

Zhong et al. [6] performed a study on visible light catalysis of graphite carbon nitride-silica composite material and its potential as a surface treatment of cement. Graphite carbon nitride-silica composite materials were synthesized by thermal polymerization using nanosilica and urea as raw materials. The effect of nanosilica content and specific surface area were investigated towards optimizing the material composition. The surface of cement-based materials was treated with graphite carbon nitride-silica composite materials by the one-sided immersion and brushing methods for the study of photocatalytic performance. By comparing the degradation effect of Rhodamine B, it was found that the painting method is more suitable for the surface treatment of cement. In addition, through the reaction of calcium hydroxide and graphite carbon nitride-silica composite materials, it was found that the combination of graphite carbon nitride-silica composite materials and cement is through $\mathrm{C}-\mathrm{S}-\mathrm{H}$ gel. Another approach towards the production of photocatalytic cementitious composites was proposed by Wang et al. [7]. $\mathrm{TiO}_{2} @ \mathrm{SiO}_{2}$ core-shell nanocomposites with different coating thicknesses were synthesized by varying the experiment parameters. Authors reported that the introduction of $\mathrm{SiO}_{2}$ coatings accelerated the rhodamine $\mathrm{B}$ removal to a certain extent, owing to its 
high surface area; however, more $\mathrm{SiO}_{2}$ coatings decreased its photocatalytic efficiencies. The cement matrix treated with $\mathrm{TiO}_{2} @ \mathrm{SiO}_{2}$ core-shell nanocomposites showed good photocatalytic efficiency and durability after harsh weathering processing. A reaction mechanism was revealed by the reaction of $\mathrm{TiO} 2 @ \mathrm{SiO}_{2}$ nanocomposites with $\mathrm{Ca}(\mathrm{OH})_{2}$.

Abd Elrahman et al. [8] performed a study towards the development of insulating light-weight cementitious composites in order to reduce the energy loss and consumption in buildings. Three different approaches towards incorporating air voids in cement pastes were proposed by introducing: aluminum powder, air-entraining agent, and hollow microspheres. A comprehensive evaluation of oven-dry density, compressive strength, porosity, water absorption, and thermal conductivity was performed. Moreover, $\mathrm{X}$-ray micro-computed tomography (micro-CT) was adopted to investigate the microstructure of the air-entrained cement pastes. Meaningful relations between each type of air-entraining method were established. The experimental results obtained showed that specimens with an admixture of hollow microspheres can improve the compressive strength of cement composites compared to other air-entraining admixtures at the same density level. It was also confirmed that the incorporation of aluminum powder creates large voids, which have a negative effect on specimens' strength and absorption.

Hwang et al. [9] studied the effects of the aggregate surface conditions on the compressive strength of quick-converting track concrete (QTC). The compressive strength of QTC and interfacial fracture toughness (IFT) were investigated by changing the amount of fine abrasion dust particles (FADPs) on the aggregate surface from 0.00 to $0.15 \mathrm{wt} \%$ and the aggregate water saturation from 0 to $100 \%$. Significant relations between the effects of aggregate water saturation on the compressive strength of the QTC and IFT were reported in correspondence to the amount of FADPs. As an outcome of this comprehensive research, fundamental knowledge of the importance of the aggregate surface conditions for the strength development of QTC was presented.

Istoan et al. [10] performed a study on the production of lightweight mortars containing hemp shiv, volcanic rocks, and white cement. A complex study covering the evaluation of the chemical, acoustic, thermal, and mechanical properties as well as fire (heat) resistance were performed. Interesting relations between the constituents and effects on the various material on the selected properties were comprehensively evaluated. As an outcome of this study, sustainable cementitious mortar with increased indoor comfort performance was produced.

Ren et al. [11] performed a study towards understanding the underlying mechanism of inhibition of the alkali-carbonate reaction (ACR) using fly ash. Authors reported that when the alkali equivalent (equivalent $\mathrm{Na}_{2} \mathrm{Oeq}$ ) of the cement is $1.0 \%$, the addition of $30 \%$ fly ash can significantly inhibit the expansion in low-reactivity aggregates, while for moderately reactive aggregates, the expansion rate can also be reduced by adding 30\% of fly ash. The study showed that fly ash refines the pore structure of the cement paste, thus the alkali migration rate in the curing solution to the interior of the concrete microbars is reduced. As the content of fly ash increases, the concentrations of $\mathrm{K}^{+}$and $\mathrm{Na}^{+}$, and the $\mathrm{pH}$ value in the pore solution gradually decrease. This makes the ACR in the rocks slower, such that the cracks are reduced, and the expansion due to the ACR is inhibited.

In addition to the experimental studies, Kim et al. [12] proposed a numerical method for inversely estimating the spatial distribution characteristic of a material's elastic modulus using the measured value of the observation data and the distance between the measurement points. In this study, the structural factors with randomness are typically modeled as having a certain probability distribution (probability density function) and a probability characteristic (mean and standard deviation). To overcome the limitations of previous studies with uncertainties, Kim et al. propose a method to numerically define the spatial randomness of the material's elastic modulus and confirm factors such as response variability and response variance so that the material properties can be predicted using the proposed method.

The above-mentioned articles are of cement-based composites with different approaches, and these studies can contribute to the development of advanced cement-based materials significantly. 
Author Contributions: Writing-original draft, P.S. and S.-Y.C.; Writing—review \& editing, P.S. and S.-Y.C. All authors have read and agreed to the published version of the manuscript.

Funding: P.S. wishes to acknowledge that this special issue was launched thanks to his Postdoctoral research stay which has received funding from the European Union's Horizon 2020 research and innovation program under the Marie Skłodowska-Curie grant agreement No. 841592.

Acknowledgments: We thank all the authors who contributed to this special issue for preparing interesting papers as well as reviewers who shared their valuable time for reviewing these publications. P.S. is Supported by the Polish Foundation for Science.

Conflicts of Interest: The authors declare no conflict of interest.

\section{References}

1. Marcalikova, Z.; Čajka, R.; Bilek, V.; Bujdos, D.; Sucharda, O. Determination of Mechanical Characteristics for Fiber-Reinforced Concrete with Straight and Hooked Fibers. Crystals 2020, 10, 545. [CrossRef]

2. Smarzewski, P. Study of Bond Strength of Steel Bars in Basalt Fibre Reinforced High Performance Concrete. Crystals 2020, 10, 436. [CrossRef]

3. Jiang, F.; Deng, M.; Mo, L.; Wu, W. Influence of Combined Action of Steel Fiber and MgO on Chloride Diffusion Resistance of Concrete. Crystals 2020, 10, 338. [CrossRef]

4. Cheng, Q.; Zhang, J.; Zhou, N.; Guo, Y.; Pan, S. Experimental Study on Unconfined Compression Strength of Polypropylene Fiber Reinforced Composite Cemented Clay. Crystals 2020, 10, 247. [CrossRef]

5. Lehner, P.; Konečný, P.; Ponikiewski, T. Comparison of Material Properties of SCC Concrete with Steel Fibres Related to Ingress of Chlorides. Crystals 2020, 10, 220. [CrossRef]

6. Zhong, W.; Wang, D.; Jiang, C.; Lu, X.; Zhang, L.; Cheng, X. Study on Visible Light Catalysis of Graphite Carbon Nitride-Silica Composite Material and Its Surface Treatment of Cement. Crystals 2020, 10, 490. [CrossRef]

7. Wang, D.; Geng, Z.; Hou, P.; Yang, P.; Cheng, X.; Huang, S. Rhodamine B Removal of $\mathrm{TiO}_{2} @ \mathrm{SiO}_{2} \mathrm{Core}^{-S h e l l}$ Nanocomposites Coated to Buildings. Crystals 2020, 10, 80. [CrossRef]

8. Elrahman, M.A.; El Madawy, M.E.; Chung, S.-Y.; Majer, S.; Youssf, O.; Sikora, P. An Investigation of the Mechanical and Physical Characteristics of Cement Paste Incorporating Different Air Entraining Agents using X-ray Micro-Computed Tomography. Crystals 2020, 10, 23. [CrossRef]

9. Hwang, R.; Lee, I.; Pyo, S.; Kim, D.J. Influence of the Aggregate Surface Conditions on the Strength of Quick-Converting Track Concrete. Crystals 2020, 10, 543. [CrossRef]

10. Istoan, R.; Tămaș-Gavrea, D.R.; Manea, D.L. Experimental Investigations on the Performances of Composite Building Materials Based on Industrial Crops and Volcanic Rocks. Crystals 2020, 10, 102. [CrossRef]

11. Ren, X.; Li, W.; Mao, Z.; Deng, M. Inhibition of the Alkali-Carbonate Reaction Using Fly Ash and the Underlying Mechanism. Crystals 2020, 10, 484. [CrossRef]

12. Kim, D.-Y.; Sikora, P.; Araszkiewicz, K.; Chung, S.-Y. Inverse Estimation Method of Material Randomness Using Observation. Crystals 2020, 10, 512. [CrossRef] 